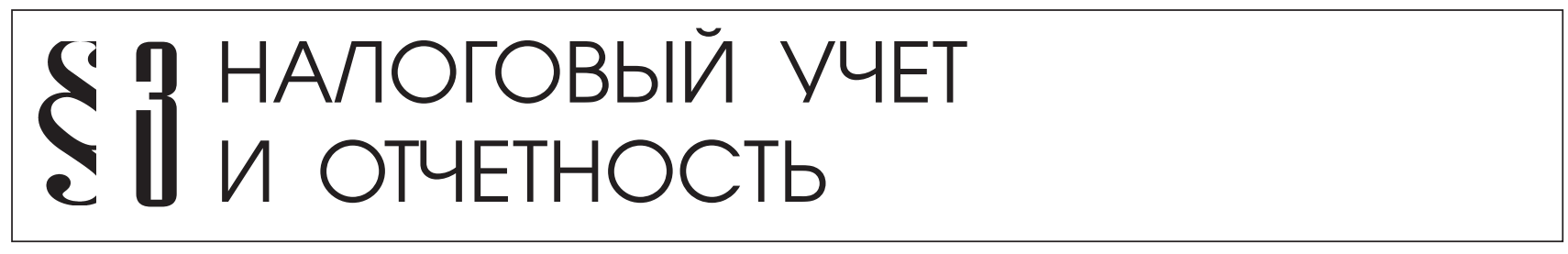

Баженов А.А.

\title{
ПРОБЛЕМЫ ОТРАЖЕНИЯ ЗАДОЛЖЕННОСТИ ПО НАЛОГАМ И СБОРАМ В БУХГАЛТЕРСКОЙ (ФИНАНСОВОЙ) ОТЧЕТНОСТИ
}

Аннотация: В данной статье представлен дискуссионный подход к отражению задолженности по налогам и сборам в бухгалтерской (финансовой) отчетности. Показано, что в традиционном способе отражения в бухгалтерской (финансовой) отчетности задолженности по налогам и сборам в разрезе отдельных налогов (не сальдированном) можно усомниться, поскольку аналитический учет согласно действующему законодательству необходимо организовывать по видам налогов, а именно: федеральным, региональным и местным. Именно в разрезе таких укрупненных групп и необходимо организовывать бухгалтерский учет и отражать в бухгалтерской (финансовой) отчетности задолженность по налогам и сборам (свернуто), не завышая при этом валюту бухгалтерского баланса. Также показано, что предлагаемый подход к отражению налоговых обязательств в бухгалтерской (финансовой) отчетности полностью корреспондирует с действующим правилом зачета недоимок и переплат по налогам в рамках статьи 78 НК РФ (самостоятельный зачет налоговым органом по видам налогов и сборов при предъявлении налогоплательщику требования на сумму образовавшейся недоимки).

Review: This article presents a debatable approach to reflecting taxes and levies debts in accounting (financial) reports. It is shown that traditional accounting (financial) reporting on debts in taxes and levies for specific types of taxes (non-balanced) is quite doubtful, since according to the current legislation analytical reporting should be organized based on types of taxes (federal, regional, and local?). And one should use these enlarged groups of taxes for the organization of accounting (financial) reporting of taxes and levies debts (folded) without overstating the currency of accounting balance. It is also shown that the approach of the author to the reflection of tax obligations in accounting (financial) reporting fully corresponds with the current rules for the offsetting of taxes in arrears and overpays under Art. 78 of the Tax Code of the Russian Federation (unilateral offsetting by a tax body according to the types of taxes and levies when bringing a claim to a taxpayers for taxes and levies in arrears).

Ключевые слова: налог, вид, аналитический, бухгалтерский, учет, отчетность, зачет, задолженность, валюта, баланс

Keywords: tax, types, analytical, accounting, calculation, reporting, offsetting, arrears, currency, balance sheet.

662

(C) NOTA BENE (ОOО «НБ-Медиа») www.nbpublish.com 
соответствии сп. 6 Положения по бухгалтерскому учету «Бухгалтерская отчетность организации» (ПБУ 4/99)», утвержденного Приказом Минфина РФ от 06.07.1999 №43н (с изменениями и дополнениями) (далее - ПБУ 4/99) достоверной и полной считается бухгалтерская отчетность, сформированная исходя из правил, установленных нормативными актами по бухгалтерскому учету1.

Одним из таких правил, предусмотренных п. 34 ПБУ 4/99, а также п. 40 Положения по ведению бухгалтерского учета и бухгалтерской отчетности в Российской Федерации, утвержденного Приказом Минфина РФ от 29.07.1998 №34н (с изменениями и дополнениями) ${ }^{2}$ (далее - Положение №34н), является недопустимость зачета между статьями активов и пассивов, статьями прибылей и убытков, кроме случаев, когда такой зачет предусмотрен соответствующими положениями по бухгалтерскому учету.

В настоящей статье будет рассмотрен подход к отражению в бухгалтерской (финансовой) отчетности активов и обязательств по налогам и сборам с возможностью их зачета между собой.

Изучая историю вопроса, в специальной литературе можно наблюдать следующую картину.

Так, специалисты АO «Консультант Плюс» в Путеводителе по налогам «Прак-

\footnotetext{
${ }^{1}$ Об утверждении Положения по бухгалтерскому учету «Бухгалтерская отчетность организации» (ПБУ 4/99): Приказ Минфина РФ от 06 июля 1999 г. №43н // Финан. газ. - 1999. - №34, Экон. и жизнь. - 1999. - №35.

2 Об утверждении Положения по ведению бухгалтерского учета и бухгалтерской отчетности в Российской Федерации: Приказ Минфина РФ от 29 июля 1998 г. №34н // Бюлл. норм. акт. федер. орг. исполнит. влас. - 14.09.1998. - №23, Росс. газ. («Ведомст. прилож.») 31.10.1998. - №208.
}

тическое пособие по годовой бухгалтерской отчетности - 2012» указывают на то, что дебетовые и кредитовые остатки по разным налогам, сборам и взносам не сальдируются.

Ведущий аудитор фирмы «ЭкстраАудит» Е.П. Столбов в статье «Рекомендации по проверке годовой бухгалтерской отчетности», опубликованной в журнале «Налоговый вестник» №12 за 2009 год (C. 93 - 101) также придерживается мнения, что в бухгалтерской (финансовой) отчетности не допускается зачет между статьями активов и пассивов, статьями прибылей и убытков, кроме случаев, когда такой зачет предусмотрен соответствующими положениями по бухгалтерскому учету. Но в свою очередь он поясняет, что сальдо по обязательствам (в т.ч. по видам налогов) счета 68 «Расчеты по налогам и сборам» в бухгалтерском балансе отражаются «развернуто» (не «сворачиваются»- не суммируются), т.е. имеющееся дебетовое сальдо (по каждому виду налога) показываются в соответствующей статье (показателе) актива баланса, а кредитовое - в соответствующей статье (показателе) пассива.

В статье Палициной И. «Аналитический аспект дебиторской и кредиторской задолженности», опубликованной в журнале «Практическая бухгалтерия» №7 за 2009 год, автор указывает на то, что объединение показателей субсчетов расчетов с бюджетом приводит к искажению бухгалтерской (финансовой) отчетности. Так, например, недоимка по налогу на прибыль организаций в один бюджет не погашает переплату в другой бюджет. В этом случае переплату следует отражать в активе, а недоимку - в пассиве баланса.

Ведущий консультант консалтинговой группы «Руна» Л.Г. Жадан в своем ответе на вопрос главного бухгалтера Н.В. Скобенко 


\section{Налоги и налогообложение - №9(111) • 2013}

в журнале «Главбух» №14 за 2006 год, дал однозначный ответ, что при заполнении бухгалтерского баланса дебетовое сальдо по субсчетам счета 68 «Расчеты по налогам и сборам» надо показать в активе баланса по строке 240 «Дебиторская задолженность (платежи по которой ожидаются в течение 12 месяцев после отчетной даты)» (в настоящее время это строка 1230 «Дебиторская задолженность»), а кредитовое сальдо отражают в пассиве баланса по строке 624 «Задолженность по налогам и сборам» (в настоящее время это строка 1520 «Кредиторская задолженность»).

Как видно все специалисты в один голос утверждают, что зачет между отдельными налогами (при наличии дебетового и кредитового сальдо по субсчетам) при формировании бухгалтерской (финансовой) отчетности невозможен.

Но так ли это на самом деле попробуем разобраться.

Главная мысль идеи состоит в том, что зачет между статьями активов и пассивов допустим, если он осуществляется на уровне аналитического учета, то есть учета, который ведется в лицевых, материальных и иных аналитических счетах бухгалтерского учета, группирующих детальную информацию об имуществе, обязательствах и о хозяйственных операциях внутри каждого синтетического счета. Этот довод подтверждается требованиями к аналитическому учету, например, по расчетам с поставщиками и подрядчиками.

Согласно Плану счетов бухгалтерского учета финансово-хозяйственной деятельности организаций и Инструкции по его применению, утвержденных Приказом Минфина РФ от 31.10.2000 №94н (с изменениями дополнениями) (далее - План счетов) предусмотрено, что аналитический учет по счету 60 «Расчеты с поставщиками и подрядчиками» ведется по каждому предъявленному счету, а расчетов в порядке плановых платежей - по каждому поставщику и подрядчику. При этом построение аналитического учета должно обеспечить возможность получения необходимых данных по: поставщикам по акцептованным и другим расчетным документам, срок оплаты которых не наступил; поставщикам по не оплаченным в срок расчетным документам; поставщикам по неотфактурованным поставкам; авансам выданным; поставщикам по выданным векселям, срок оплаты которых не наступил; поставщикам по просроченным оплатой векселям; поставщикам по полученному коммерческому кредиту и др. ${ }^{3}$

Таким образом, аналитический учет по каждому предъявленному счету не дает возможность зачета кредиторской задолженности на дебиторскую задолженность в бухгалтерской (финансовой) отчетности, если поставщик является одновременно и покупателем. Аналогичная ситуация имеет место при организации аналитического учета по счету 62 «Расчеты с покупателями и заказчиками» (аналитический учет ведется по каждому предъявленному покупателям (заказчикам) счету).

Что касается счета 68 «Расчеты по налогам и сборам», то согласно Плану счетов аналитический учет по данному счету ведется по видам налогов.

\footnotetext{
${ }^{3}$ Об утверждении Плана счетов бухгалтерского учета финансово-хозяйственной деятельности организаций и Инструкции по его применению: Приказ Минфина РФ от 31 окт. 2000 г. №94н // Финан. газ. - 2000. - №46 (Приказ), Финан. газ. - 2000. - №47 (План счетов), Экон. и жизнь. -2000 . - №46.
} 
Понятие «вид налога» у многих учетных работников отождествляется с перечнем налогов и сборов, который организуется на отдельных субсчетах к счету 68 «Расчеты по налогам и сборам»:

- 68.1 «Налог на доходы физических лиц»;

- 68.2 «Налог на добавленную стоимость»;

- 68.3 «Акцизы»;

- 68.4 «Налог на прибыль организаций»;

- 68.7 «Транспортный налог»;

- 68.8 «Налог на имущество» и т.д.

Однако на деле это не совсем так. Понятие «вид налога» закреплено на законодательном уровне. В соответствии с п. 1 статьи 12 Налогового кодекса Российской Федерации (НК РФ) предусмотрено, что в Российской Федерации устанавливаются следующие виды налогов и сборов: федеральные, региональные и местные 4 .

К федеральным налогам и сборам, которые исчисляют и перечисляют с бюджетную систему организации (в качестве налогоплательщиков или налоговых агентов), согласно статье 13 НК РФ относятся:

- налог на добавленную стоимость;

- акцизы;

- налог на доходы физических лиц;

- налог на прибыль организаций;

- налог на добычу полезных ископаемых;

- водный налог;

- сборы за пользование объектами животного мира и за пользование объектами водных биологических ресурсов;

- государственная пошлина.

Кроме приведенных выше налогов и сборов к федеральным налогам относятся и

\footnotetext{
${ }^{4}$ Налоговый кодекс Российской Федерации. Часть первая от 31 июл. 1998 г. №146-Ф3: принят Гос. Думой Федер. Собр. Рос. Федерации 16 июл. 1998 г. // Росс. газ. 1998. - 06 авг. - №148 -149; Собр. законодательства Рос. Федерации. - 1998. - №31, ст. 3824.
}

специальные налоговые режимы (п. 7 статьи 12 НК РФ, Письмо ФНС РФ от 10.05.2006 №ММ-6-19/481@ «О списании недоимки и задолженности по пеням по специальным налоговым режимам» (вместе с Письмом Минфина РФ от 20.04.2006 №03-02-07/2-30)). Для целей формирования бухгалтерской (финансовой) отчетности организаций в соответствии с Федеральным законом от 06.12.2011 №402-Ф3 «О бухгалтерском учете» ${ }^{5}$ к специальным налоговым режимам относятся:

- система налогообложения для сельскохозяйственных товаропроизводителей (единый сельскохозяйственный налог);

- упрощенная система налогообложения;

- система налогообложения в виде единого налога на вмененный доход для отдельных видов деятельности;

- система налогообложения при выполнении соглашений о разделе продукции.

К региональным налогам согласно статье 14 НК РФ относятся:

- налог на имущество организаций;

- налог на игорный бизнес;

- транспортный налог.

К местным налогам для целей формирования бухгалтерской (финансовой) отчетности организаций согласно статье 15 НК РФ относится только земельный налог.

Перечисленные налоги и сборы, согласно Плану счетов подлежат учету на счете 68 «Расчеты по налогам и сборам» за исключением одного обстоятельства.

Планом счетов предусмотрено, что счет 68 «Расчеты по налогам и сборам» предна-

${ }^{5}$ О бухгалтерском учете: Федеральный закон от 06 декабря 2011 г. №402-Ф3 // Офиц. интернет-портал прав. информ. http://www.pravo.gov.ru, 07.12.2011, Парл. Газ. - 2011. - 09-15 декаб. №54, Рос. газ. - 2011. - 09 декаб. №278, Собр. законод. РФ. - 2011. - 12 декаб. №50, ст. 7344 . 


\section{Налоги и налогообложение - №9(111) • 2013}

значен для обобщения информации о расчетах с бюджетами по налогам и сборам, уплачиваемым организацией, и налогам с работниками этой организации. Это общая норма нормативного документа.

Согласно же специальной норме счет 68 «Расчеты по налогам и сборам» кредитуется на суммы, причитающиеся по налоговым декларациям (расчетам) ко взносу в бюджеты (в корреспонденции со счетом 99 «Прибыли и убытки» - на сумму налога на прибыль, со счетом 70 «Расчеты с персоналом по оплате труда» - на сумму налога на доходы физических лиц и т.д.).

Учитывая правовое правило приоритета специальной нормы над общей сборы за пользование объектами животного мира и за пользование объектами водных биологических ресурсов, а также государственная пошлина подлежат учету на счете 76 «Расчеты с прочими дебиторами и кредиторами», поскольку по данным сборам в налоговый орган налоговые декларации и расчеты по авансовым платежам не предоставляются.

Как видно аналитический уровень учета налогов и сборов должен быть организован более укрупненно по сравнению с традиционно принятым. В этой связи можно задать соответствующие вопросы к разработчикам программы 1C: Бухгалтерия, почему данная программа в аналитическом учете предусматривает совсем не те структурные элементы, которые необходимы для должного учета и впоследствии для формирования достоверной бухгалтерской (финансовой) отчетности.

Поэтому в разрезе именно таких укрупненных групп и необходимо организовывать бухгалтерский учет и отражать в бухгалтерской (финансовой) отчетности задолженность по налогам и сборам (свернуто), не завышая при этом валюту бухгалтерского баланса.
Существующий аналитический учет по счету 68 «Расчеты по налогам и сборам» (в разрезе каждого налога), по мнению автора, также не соответствует подходу, применяемому в настоящее время, в отношении зачета недоимок и переплат по налогам и сборам.

В соответствии с п. 1 статьи 78 НК РФ с 1 января 2008 года зачет сумм излишне уплаченных федеральных налогов и сборов, региональных и местных налогов производится по соответствующим видам налогов и сборов, а также по пеням, начисленным по соответствующим налогам и сборам.

Норма НК РФ указывает на то, что теперь не уровень бюджета определяет состояние расчетов по налогам и сборам, а вид налога, то есть, например, переплата по налогу на добавленную стоимость в полном объеме может быть зачтена в погашение недоимки по налогу на прибыль организаций как по федеральному бюджету $(2 \%)$, так и по региональному бюджету $(18 \%)$, поскольку оба налога являются налогами одного вида - федеральные, и напротив, недоимка по налогу на прибыль организаций по региональному бюджету $(18 \%)$ не может быть погашена переплатой по налогу на имущество организаций, поскольку данные налоги относятся к разными видам: федеральному и региональному соответственно.

Имея задолженность по одному налогу и переплату по другому в рамках одного вида организация вправе сальдировать результаты и отразить в бухгалтерской (финансовой) отчетности свернуто. Это действие возможно только при наличии полученного от налогового органа требования об уплате налога, по которому возникла недоимка. 
Это обстоятельство полностью корреспондирует с действиями, осуществляемыми налоговым органом в соответствии с НК РФ.

Дело в том, что согласно п. 5 статьи $78 \mathrm{HK}$ РФ зачет суммы излишне уплаченного налога в счет погашения недоимки по иным налогам, задолженности по пеням и (или) штрафам, подлежащим уплате или взысканию в случаях, предусмотренных НК РФ, производится налоговыми органами самостоятельно.

При этом в случае, предусмотренном п. 5 статьи 78 НК РФ, решение о зачете суммы излишне уплаченного налога принимается налоговым органом в течение 10 дней со дня обнаружения им факта излишней уплаты налога или со дня подписания налоговым органом и налогоплательщиком акта совместной сверки уплаченных им налогов, если такая совместная сверка проводилась, либо со дня вступления в силу решения суда.

Следует учитывать и тот факт, что положение, предусмотренное настоящим пунктом, не препятствует налогоплательщику представить в налоговый орган письменное заявление о зачете суммы излишне уплаченного налога в счет погашения недоимки (задолженности по пеням, штрафам). В этом случае решение налогового органа о зачете суммы излишне уплаченного налога в счет погашения недоимки и задолженности по пеням, штрафам принимается в течение 10 дней со дня получения указанного заявления налогоплательщика или со дня подписания налоговым органом и этим налогоплательщиком акта совместной сверки уплаченных им налогов, если такая совместная сверка проводилась ${ }^{6}$.

\footnotetext{
${ }^{6}$ Налоговый кодекс Российской Федерации. Часть первая от 31 июл. 1998 г. №146-Ф3: принят Гос. Думой Федер. Собр. Рос. Федерации 16 июл. 1998 г. // Росс. газ. 1998. - 06 авг. - №148 -149; Собр. законодательства Рос. Федерации. - 1998. - №31, ст. 3824.
}

НК РФ не разъясняет, вправе ли налоговый орган самостоятельно зачесть переплату в счет недоимки, не известив налогоплательщика о ее наличии и не предложив уплатить ее в установленный срок.

Официальной позиции по данному вопросу нет, однако есть судебное решение, согласно которому до проведения самостоятельного зачета налоговый орган обязан направить налогоплательщику требование об уплате недоимки.

Так в Постановлении ФАС ВосточноСибирского округа от 11.03.2010 по делу №A58-3149/2009 отмечено со ссылкой на позицию, изложенную в Определении Конституционного Суда РФ от 08.02.2007 №381-О-П, что самостоятельный зачет фактически является разновидностью (формой) уплаты налога. Значит, для проведения зачета необходимо соблюдение требований, установленных НК РФ для взыскания недоимки. Уплата недоимки самостоятельно налогоплательщиком связывается с направлением требования об уплате налога в соответствии со статьями 69 и 70 НК РФ, поэтому для проведения зачета налоговый орган должен уведомить налогоплательщика требованием о возникшей недоимке.

\section{Выводы:}

1. Традиционный способ отражения в бухгалтерской (финансовой) отчетности задолженности по налогам и сборам в разрезе отдельных налогов (не сальдированный) ставиться под сомнение, поскольку аналитический учет согласно действующему законодательству необходимо организовывать по видам налогов.

2. Под видами налогов следует понимать установленные в Российской Федерации 
DOI: $10.7256 / 1812-8688.2013 .7 .9002$

При цитировании этой статьи сноска на доі обязательна

\section{Налоги и налогообложение - №9(111) • 2013}

виды налогов и сборов, а именно: федеральные, региональные и местные. Именно в разрезе таких укрупненных групп и необходимо организовывать бухгалтерский учет и отражать в бухгалтерской (финансовой) отчетности задолженность по налогам и сборам (свернуто), не завышая при этом валюту бухгалтерского баланса.

3. Предлагаемый подход к отражению налоговых обязательств в бухгалтерской (финансовой) отчетности полностью корреспондирует с действующим правилом зачета недоимок и переплат по налогам в рамках статьи 78 НК РФ (самостоятельный зачет налоговым органом по видам налогов и сборов при предъявлении налогоплательщику требования на сумму образовавшейся недоимки).

\section{Библиография:}

1. Баженов А.А. Федеральные налоги и сборы: учебное пособие в схемах / А.А. Баженов; М-во образования и науки Рос. Федерации, ФГБОУ ВПО Владим. гос. ун-т - Владимир: Транзит-Икс, 2013. - 82 с.

2. Баженов А.А., Гудков А.С. Бухгалтерская отчетность и некоторые особенности ее формирования. Вестник филиала ВЗФЭИ в г. Владимире: периодич. научн. изд. / Мин-во обр. и науки РФ; ВЗФЭИ, филиал в г. Владимире. Вып.3. - Владимир: ООО “Сервис-Принт”, 2009.-С. 10-11.

3. Баженов А.А., Гудков А.С. Тест: Знаете ли вы правила формирования бухгалтерской отчетности? // Вестник профессиональных бухгалтеров, №1.-М: ООО “Издательский дом БИНФА”, 2009. - С. 30 - 31.
4. Диркова Е.Ю. Расчеты по налогам в бухгалтерском учете и отчетности // “Налоговая политика и практика", 2010, №12.

5. Иоффе Л. Годовой отчет // "Практический бухгалтерский учет”, 2012, №№2, 3 .

6. Малышко В. Годовой отчет // “Практический бухгалтерский учет”, 2013, №2 .

7. Малюкова Н.С. Рекомендации по составлению годовой бухгалтерской (финансовой) отчетности организаций за 2012 г. // “Официальные материалы для бухгалтера. Комментарии и консультации”, 2013, №3.

8. Налоговый кодекс Российской Федерации. Часть первая от 31 июл. 1998 г. №146-Ф3: принят Гос. Думой Федер. Собр. Рос. Федерации 16 июл. 1998 г. // Росс. газ.-1998.-06 авг. - №148-149; Собр. законодательства Рос. Федерации.-1998.-№31, ст. 3824.

9. О бухгалтерском учете: Федеральный закон от 06 декабря 2011 г. №402-Ф3 // Офиц. интернет-портал прав. информ. http://www.pravo.gov.ru, 07.12.2011, Парл. Газ. - 2011. - 09-15 декаб. №54, Рос. газ.2011.-09 декаб. №278, Собр. законод. РФ. - 2011. - 12 декаб. №50, ст. 7344.

10. Об утверждении Плана счетов бухгалтерского учета финансово-хозяйственной деятельности организаций и Инструкции по его применению: Приказ Минфина РФ от 31 окт. 2000 г. №94н // Финан. газ.-2000. - №46 (Приказ), Финан. газ.-2000. - №47 (План счетов), Экон. и жизнь. - 2000.-№46.

11. Об утверждении Положения по бухгалтерскому учету “Бухгалтерская отчетность организации” (ПБУ 4/99): Приказ Минфина РФ от 06 июля 1999 г. №43н // Финан. газ.-1999. - №34, Экон. и жизнь. - 1999. - №35. 
12. Об утверждении Положения по ведению бухгалтерского учета и бухгалтерской отчетности в Российской Федерации: Приказ Минфина РФ от 29 июля 1998 г. №34н // Бюлл. норм. акт. федер. орг. исполнит. влас. - 14.09.1998. - №23, Росс. газ. (“Ведомст. прилож.”) - 31.10.1998.№208.

13. Палицина И. Аналитический аспект дебиторской и кредиторской задолженности // “Практическая бухгалтерия", 2009, №7.

14. Столбов Е.П. Рекомендации по проверке годовой бухгалтерской отчетности // “Налоговый вестник”, 2009. №12. С. 93-101.

15. Тяпухин С.В. Отдельные вопросы составления бухгалтерской отчетности // “Торговля: бухгалтерский учет и налогообложение”, 2013, №2

\section{References (transliteration):}

1. Bazhenov A.A. Federal'nye nalogi i sbory: uchebnoe posobie v shemah / A.A. Bazhenov; M-vo obrazovaniya i nauki Ros. Federacii, FGBOU VPO Vladim. gos. un-t - Vladimir: Tranzit-Iks, 2013. - 82 s.

2. Bazhenov A.A., Gudkov A.S. Buhgalterskaya otchetnost' i nekotorye osobennosti ee formirovaniya. Vestnik filiala VZFEI v g. Vladimire: periodich. nauchn. izd. / Min-vo obr. i nauki RF; VZFEI, filial v g. Vladimire. Vyp.3. - Vladimir: OOO "Servis-Print", 2009.-S. 10-11.

3. Bazhenov A.A., Gudkov A.S. Test: Znaete li vy pravila formirovaniya buhgalterskoy otchetnosti? // Vestnik professional'nyh buhgalterov, №1.-M: OOO “Izdatel’skiy dom BINFA", 2009. - S. 30 - 31

4. Dirkova E.Yu. Raschety po nalogam v buhgalterskom uchete i otchetnosti // "Nalogovaya politika i praktika", 2010, №12.

5. Ioffe L. Godovoy otchet // "Prakticheskiy buhgalterskiy uchet”, 2012, №№2, 3.

6. Malyshko V. Godovoy otchet // "Prakticheskiy buhgalterskiy uchet”, 2013, №2.

7. Malyukova N.S. Rekomendacii po sostavleniyu godovoy buhgalterskoy (finansovoy) otchetnosti organizaciy za $2012 \mathrm{~g}$. // “Oficial'nye materialy dlya buhgaltera. Kommentarii i konsul’tacii”, 2013, №3.

8. Palicina I. Analiticheskiy aspekt debitorskoy i kreditorskoy zadolzhennosti // "Prakticheskaya buhgalteriya", 2009, №7.

9. Stolbov E.P. Rekomendacii po proverke godovoy buhgalterskoy otchetnosti // “Nalogovyy vestnik", 2009. №12. S. 93-101.

10. Tyapuhin S.V. Otdel'nye voprosy sostavleniya buhgalterskoy otchetnosti // "Torgovlya: buhgalterskiy uchet i nalogooblozhenie", 2013, №2 